\title{
Hypertriglyceridemia and Remodeling of the Left Ventricle in Patients with Chronic Kidney Disease
}

\author{
IT Murkamilovi,2, IS Sabirov², KA Aitbaev ${ }^{1}$, VV Fomin ${ }^{4}$, Zh A Murkamilova ${ }^{5}$, ZR Rayimzhanov ${ }^{1,6}$, NA Redjapova7 and \\ FA Yusupov ${ }^{7}$
}

${ }^{1}$ IK Akhunbaev Kyrgyz State Medical Academy, 92 Akhunbaev str, Bishkek

${ }^{2}$ First President of Russia BN Yeltsin Kyrgyz Russian Slavic University, 44 Kievskaya str, Bishkek

${ }^{3}$ Scientific and research Institute of molecular biology and medicine, 3 T. Moldo str, Bishkek

${ }^{4}$ IM Sechenov First Moscow State Medical University, 2 Bolshaya Pirogovskaya str, Moscow

${ }^{5}$ Family Medicine Center № 7, 3/1 T. Moldo str, Bishkek

${ }^{6}$ NN Burdenko Main Military Clinical Hospital, 3 Gospitalnaya sq., Moscow

${ }^{7}$ Osh State University, 331 Lenin str., Osh, Bishkek

*Corresponding author: IT Murkamilov, Kyrgyz State Medical Academy, Bishkek

\begin{abstract}
Aim: The aim of the study was to study the clinical and functional features of renal dysfunction in conditions of hypertriglyceridemia and remodeling of the left ventricle.

Materials and Methods: 176 patients with chronic kidney disease (CKD) were examined, 111 of them with hypertriglyceridemia (HTG) in association with left ventricular hypertrophy (LVH) 1st group and 65 patients with LVH in the absence of HTG, matched by gender and age. Along with general clinical studies, all patients were assessed for lipid spectrum parameters, measurement of cystatin C in blood plasma, and indicators of arterial stiffness (augmentation index and stiffness) and echocardiography were analyzed.

Results: In the $2^{\text {nd }}$ group (HTG + LVH), the number of patients with type 2 diabetes mellitus (DM), a combination of hypertension, coronary heart disease and gout were significantly higher $(\mathrm{p}<0.05)$. Persons with chronic obstructive pulmonary disease, chronic pyelonephritis and cerebrovascular diseases were significantly more common in the 1 st group $(\mathrm{p}<0.05)$. In the $2 \mathrm{nd}$ group, the value of BMI [(30.4 $\pm 5.2 \mathrm{~kg} / \mathrm{m}^{2}$ against $\left.28.1 \pm 5.7 \mathrm{~kg} / \mathrm{m} 2 ; \mathrm{p}=0.013\right)$, the level of systolic blood pressure (BP) $(140 \pm 19 \mathrm{~mm} \mathrm{Hg})$. v. $134 \pm 18$ mmHg; $p=0.042)$, thickness of the posterior wall of the left ventricle (LV) $(0.98 \pm 0.18 \mathrm{~cm}$ versus $0.90 \pm 0.16 \mathrm{~cm} ; p=0.008)$, relative thickness $\mathrm{LV}$ walls $(0.385 \pm 0.107$ units versus $0.357 \pm 0.060$ units; $\mathrm{p}=0.032)$, the number of patients with concentric $\mathrm{LV}$ hypertrophy (29.2; versus 13.5\%; p=0.008), total cholesterol content (5.80 (4.87;6.80) mmol/l vs. 4.75 (4.0;5.38) mmol / l; p=0.000); lowdensity lipoprotein cholesterol $(3.56(3.12 ; 4.63) \mathrm{mmol} / \mathrm{l}$ versus 3.09 (2.61;3.79) mmol/l; p=0.045) cystatin C (1.25 (1.08;1.70) mg / l versus $1.16(0.99 ; 1.42) \mathrm{mg} / \mathrm{l} ; \mathrm{p}=0.026)$ turned out to be significantly higher, and the calculated glomerular filtration rate (eGFR) significantly lower $(57.0 \pm 22 \mathrm{ml} /$ min versus $65.0 \pm 23 \mathrm{ml} / \mathrm{min} ; \mathrm{p}=0.028)]$ compared with the 1 st group. A positive correlation was noted between the level of central BP $(\mathrm{r}=0.264 ; \mathrm{p}=0.003)$, the augmentation index $(\mathrm{r}=0.224 ; \mathrm{p}=0.011)$ and plasma cystatin $\mathrm{C}(\mathrm{r}=$ $0.486 ; \mathrm{p}=0.000$ ) with the value of the indexed LV myocardium mass (LVMI) in the total sample surveyed. A negative correlation was recorded between the eGFR and LVMI ( $\mathrm{r}=-0.425$; $\mathrm{p}=0.000)$.
\end{abstract}

Conclusion: In the presence of hypertriglyceridemia in patients with left ventricular hypertrophy, cystatin C increases in blood plasma and GFR decreases with a tendency for augmentation index to increase.

Keywords: Hypertriglyceridemia; Left Ventricular Remodeling; Chronic Kidney Disease; Cystatin C 


\section{Introduction}

The number of patients with chronic kidney disease (CKD) is increasing annually, which is becoming an important medical and social problem of our time [1,2]. Patients with CKD have an increased risk of developing cardiovascular diseases (CVD), so they should be examined to identify these complications [3]. Hypertriglyceridemia (HTG) can realize its effect on the progression of renal damage through the development of intrarenal atherosclerosis and through the toxic effect of lipid particles on nephron structures [4]. It was shown that already in the early stages of CKD, the plasma TG level rises, the highest TG levels are detected in patients with nephrotic syndrome and in patients receiving renal replacement therapy (RRT) [5]. This is associated with a decrease in the activity of lipoprotein lipase enzymes and triacylglycerol lipase in the liver. Under conditions of HTG in renal dysfunction, the production of proinflammatory cytokines increases and proteinuria is aggravated, which contributes to the progression of CKD and an additional increase in cardiovascular risk [6,3]. A decrease in GFR induces the development of left ventricular hypertrophy (LVH), the frequency and severity of which determine the prognosis for CKD [7]. Structural and functional changes of the heart in CKD primarily, hypertrophy and change in the geometry of the $\mathrm{LV}$, on the one hand, are considered as a complication, and on the other, as a factor in the progression of renal dysfunction [8-10]. The combination of HTG and LVH in the general population of people has been studied sufficiently. However, there are few works where the value of HTG as an independent risk for renal dysfunction and CVD would be considered. This dictates the need to improve the early diagnosis

Table 1: Clinical and anamnestic characteristics of research patient.

\begin{tabular}{|c|c|c|c|}
\hline Nosological forms & 1-st group $(n=111)$ & 2-nd group $(n=65)$ & $P=$ \\
\hline Bronchial asthma, $\mathrm{n}(\%)$ & $7(6,3)$ & $5(7,6)$ & 0,183 \\
\hline Hypertension, n (\%) & $27(24,3)$ & $23(35,3)$ & 0,117 \\
\hline Coronary heart disease, $\mathrm{n}(\%)$ & $21(18,9)$ & $15(23,0)$ & 0,525 \\
\hline Podagra, n (\%) & $2(1,8)$ & $2(3,0)$ & 0,132 \\
\hline Type 2 diabetes, $\mathrm{n}(\%)$ & $9(8,1)$ & $14(21,5)$ & 0,000 \\
\hline The combination of type 2 diabetes and hypertension, CHD and podagra, n (\%) & $39(35,1)$ & $45(69,2)$ & 0,000 \\
\hline Chronic obstructive pulmonary disease, n (\%) & $11(9,9)$ & $3(4,6)$ & 0,000 \\
\hline Chronic glomerulonephritis, n (\%) & $14(12,6)$ & $12(18,4)$ & 0,367 \\
\hline Chronic pyelonephritis, n (\%) & $13(11,7)$ & $2(3,0)$ & 0,003 \\
\hline Cerebrovascular diseases, n (\%) & $7(6,3)$ & $2(3,0)$ & 0,001 \\
\hline
\end{tabular}

Note: CHD - coronary heart disease; Type 2 diabetes; $n$ - is the number of patients; p-credibility.

The laboratory study included an assessment parameterof lipid spectrum s (total cholesterol (cholesterol), low-density lipoprotein cholesterol (LDL cholesterol), high-density lipoprotein cholesterol (HDL cholesterol) and TG), uric acid, calcium and fibrinogen in blood. Additionally, all patients were determined by the concentration of cystatin $\mathrm{C}$ in plasma by the immunoturbidimetric method. The severity of renal dysfunction was determined on the basis of the GFR, calculated according to the F.J. Hoek formula: of heart and kidney damage in HTG. In this regard, the study of LV restructuring and the functional state of the kidneys among persons with HTG is of considerable interest.

\section{Materials and Methods}

The work was performed in the clinical departments of faculty therapy of the KSMA n.a.I.K. Akhunbaeva and therapy №2 KRSU n. a. B.N. Yeltsin, Bishkek. The study included 176 patients over the age 18 with an established diagnosis of CKD. The midddle age of the examined individuals was $52.9 \pm 13.3$ years. Diagnosis of hypertriglyceridemia [11], left ventricular hypertrophy [12] and CKD [13] were carried out in accordance with existing standards and recommendations. The study was approved by the Ethics Committee of the KSMA n.a. I.K. Akhunbaeva. Nosological characteristics of the patients included in the study are presented in Table 1. The study design is a momentary case-control study. The criteria for inclusion in the study was the presence of echocardiographic (EchoCG) signs of LVH and CKD. The study did not include individuals with endstage CKD who are on renal replacement therapy (RRT), or patients with valvular heart disease. All the examined individuals were divided into two groups depending on the TG content of the blood plasma. Group $1(\mathrm{n}=111)$ included patients with a plasma TG level $<1.7 \mathrm{mmol} / \mathrm{l}$, the 2 nd group ( $\mathrm{n}=65$ ) with plasma $\mathrm{TG} \geq 1.7 \mathrm{mmol} / \mathrm{l}$, i.e. with the presence of GTG. Physical examination included an assessment of the general condition, a clinical measurement of blood pressure (BP) in both hands in a sitting position using the Korotkov method, a was determined body mass index (BMI), was calculated and the number of heartbeats (HR). BMI was calculated using the formula: BMI = body weight $(\mathrm{kg}) /$ height $2\left(\mathrm{~m}^{2}\right)$.
GFR $=80.35$ / Cys-4.32 [14]. The instrumental part of the work consisted of studying the parameters of arterial stiffness and augmentation (Alp, augmentation index) using the Angioscan-01 device (AngioScan Electronics LLC, Russia) [15]. Transthoracic EchoCG with simultaneous tissue myocardial dopplerography was performed on a Vivid Q ultrasound scanner (USA, 2014) according to the standard technique. The thickness of the walls, the dimensions of the left ventricular cavity (LV), the diameter of the exit 
aorta $(\mathrm{cm})$ and left atrium $(\mathrm{cm})$ were estimated from parasternal access along the long axis of the LV. Measured the thickness of the interventricular septum (IVS, $\mathrm{cm}$ ) and the posterior wall of the left ventricle $(\mathrm{LV}, \mathrm{cm})$ in diastole, the final diastolic (FDM, $\mathrm{cm})$ and the final systolic dimensions (FDM, cm) of LV were determined.

LV systolic function was estimated by its ejection fraction (EF, $\%$ ), which was calculated using the formula L.E. Teichholtz (1976) in the absence of zones of hypo- and akinesis [16]. In order to assess the diastolic function of the left ventricle in the mode of pulsed Doppler sonography, the transmitral diastolic flow rate (E / A) and the time of blood flow slowing down of the early diastolic filling of the left ventricle (DT) were measured. The LV myocardium mass (MLMH) was calculated by the formula R.B. Devereux et al [17]. The LV myocardial mass index (LVMH) was defined as the ratio of LVML to body surface area. The criteria for LVH and types of LV myocardial remodeling were determined in accordance with the recommendations of ESC from 2018 [12]. For the assessment of LVHL, the LVMI was calculated, the upper value of which was 95 $\mathrm{g} / \mathrm{m}^{2}$ for women and $115 \mathrm{~g} / \mathrm{m}^{2}$ for men. The relative wall thickness (RWT) of the LV was calculated for each patient as (IVM + LVLS)/ LV CRD. For an increase in RWT, was taken a value of more than 0.42 [12]. The criteria of concentric and eccentric variants of LVHL were considered to be LVMI values greater than normal, RWT> 0.42 and LVMI higher than normal, but RWT $<0.42$, respectively. Statistical analysis of the data was carried out using the software package "Statistica 10.0". All quantitative variables are presented as mean \pm standard deviation, medians and quartiles [Me (Q25; Q75)]. Significance of differences between groups was assessed using t-Student test (for variables with a normal distribution) and the Mann-Whitney test (for variables with a non-parametric distribution) [18]. Correlation analysis was carried out by the Pearson criterion - for variables with a normal distribution and the Spearman coefficient (for variables with a non-parametric distribution). For all types of analysis, $\mathrm{p}<0.05$ were considered statistically significant.

\section{Results of Research}

The distribution of patients with LVH without HTG and with HTG is presented in Table 1. Among the examined groups with HTG, the proportion of patients suffering from type 2 diabetes mellitus (DM) and its combination with hypertension, coronary disease, and gout was significantly higher in the $2^{\text {nd }}$ group compared with the 1st group. In contrast, individuals with chronic obstructive pulmonary disease (COPD), chronic pyelonephritis and cerebrovascular diseases (CVD) were significantly more common in the 1st group. When assessing the general characteristics of the studied groups, it was noted that the initial patients were similar in age and sex (Table 2). In the $2^{\text {nd }}$ group, i.e. in patients with HTG, the value of BMI was significantly higher $\left(30.4 \pm 5.2 \mathrm{~kg} / \mathrm{m}^{2}\right.$ against $28.1 \pm 5.7 \mathrm{~kg} / \mathrm{m}^{2} ; \mathrm{p}=0.013$ ) compared with the 1 st group. Analysis of hemodynamic parameters showed a higher level of systolic blood pressure $(140 \pm 19 \mathrm{~mm} \mathrm{Hg}$ versus $134 \pm 18 \mathrm{~mm} \mathrm{Hg}$; $=0.042)$ in the group of individuals with HTG compared with the 1st group. It should be noted that there were no intergroup differences in heart rate, diastolic and central blood pressure, augmentation index and stiffness (Table 2). According to EchoCG, the diameter of the output aorta, the end systolic and diastolic size of the LV, the longitudinal size of the left atrium, the LV ejection fraction and LVMLI did not differ significantly. There was a tendency to increase the thickness of the IUP in the group of persons with HTG. At the same time, in this group there was a statistically significant increase in the SLWL thickness (Table 2). All examined individuals in both groups had similar LVML, E/A and DT LV values. Significant differences between patients of the two compared groups were determined in terms of LV RWT. As can be seen from Table 2, the RWT of LV patients of the $2^{\text {nd }}$ group significantly exceeded the RWT of the LV patients of the $1^{\text {st }}$ group (p=0.032).

Table 2: Clinical - laboratory parameters of the examined patients with CKD.

\begin{tabular}{|c|c|c|c|}
\hline Indicators & $\begin{array}{l}\text { 1-st group } \\
(n=111)\end{array}$ & $\begin{array}{l}2 \text {-nd group } \\
\qquad(n=65)\end{array}$ & $P=$ \\
\hline Age years & $52,9 \pm 12,7$ & $53,0 \pm 14,3$ & 0,967 \\
\hline Gender female/male & $60 / 51$ & $31 / 34$ & 0,417 \\
\hline Body mass index, $\mathrm{kg} / \mathrm{m}^{2}$ & $28,1 \pm 5,7$ & $30,4 \pm 5,2$ & 0,013 \\
\hline $\mathrm{HR}$, beats/min & $77 \pm 13$ & $81 \pm 14$ & 0,104 \\
\hline $\begin{array}{c}\text { Systolic blood pressure, } \mathrm{mm} \\
\text { Hg. st. }\end{array}$ & $134 \pm 18$ & $140 \pm 19$ & 0,042 \\
\hline $\begin{array}{c}\text { Diastolic blood pressure, } \mathrm{mm} \\
\text { Hg. st. }\end{array}$ & $82 \pm 9$ & $85 \pm 9$ & 0,167 \\
\hline $\begin{array}{c}\text { Central blood pressure, } \mathrm{mm} \\
\text { Hg. st. }\end{array}$ & $131 \pm 19$ & $137 \pm 20$ & 0,068 \\
\hline Index of augmentation, $\%$ & $48,2 \pm 15,0$ & $47,5 \pm 14,6$ & 0,709 \\
\hline Stiffness index, \% & $105,2 \pm 25,2$ & $101,6 \pm 23,7$ & 0,232 \\
\hline The diameter of the aorta, cm & $4,08 \pm 0,56$ & $3,24 \pm 0,31$ & 0,485 \\
\hline $\begin{array}{l}\text { The longitudinal size of the left } \\
\text { atrium, cm }\end{array}$ & $3,73 \pm 0,55$ & $3,81 \pm 0,45$ & 0,325 \\
\hline The final diastolic size of $\mathrm{LV}, \mathrm{cm}$ & $5,06 \pm 0,43$ & $5,11 \pm 0,51$ & 0,547 \\
\hline Final systolic LV size, cm & $3,42 \pm 0,47$ & $3,24 \pm 0,52$ & 0,629 \\
\hline Thickness of MWP, cm & $0,91 \pm 0,17$ & $0,97 \pm 0,19$ & 0,051 \\
\hline Thickness PWLV, cm & $0,90 \pm 0,16$ & $0,98 \pm 0,18$ & 0,008 \\
\hline LV ejection fraction, $\%$ & $67 \pm 8$ & $66 \pm 8$ & 0,491 \\
\hline E/A LV & $0,939 \pm 0,296$ & $0,905 \pm 0,291$ & 0,499 \\
\hline DT LV, ms & $192,8 \pm 33,7$ & $199,4 \pm 40,5$ & 0,302 \\
\hline Relative wall thickness, units & $0,357 \pm 0,060$ & $0,385 \pm 0,107$ & 0,032 \\
\hline $\begin{array}{l}\text { Indexed mass of } \mathrm{LV} \\
\text { myocardium, } \mathrm{g} / \mathrm{m}^{2}\end{array}$ & $150,3 \pm 36,2$ & $156,2 \pm 40,0$ & 0,338 \\
\hline Eccentric LVH, n (\%) & $96(86,5)$ & $46(70,8)$ & 0,015 \\
\hline Concentric LVH, n (\%) & $15(13,5)$ & $19(29,2)$ & 0,008 \\
\hline
\end{tabular}

Note: $\mathrm{n}$ - is the number of patients; $\mathrm{p}$ - reliability; HR - heart rate; $\mathrm{BP}$ - blood pressure; LV - left ventricle; LVH - left ventricular hypertrophy; DT is the flow deceleration time. 
Analysis of the frequency of occurrence of types of LV restructuring of the two compared groups showed a significant difference in values $(\mathrm{p}<0.05)$. Thus, the proportion of patients with a concentric type of LVH was significantly higher among patients with HTG (29.2\% vs. $13.5 \%$; $=0.008)$, and the eccentric type significantly prevailed in the 1 st group $(86.5 \%$ vs. 70.8 $\% ; \mathrm{p}=0.015)$. At the next stage of the study, were analyzed the biochemical parameters of the examined groups, the results of the analysis are presented in Table 3. As was to be expected, in the group of individuals with HTG, the median total cholesterol, TG and LDL cholesterol was significantly higher $(\mathrm{p}<0.05)$. The calcium content and the number of patients with an increase in CRP in the blood plasma were equivalent in both groups. A clinically significant increase in plasma uric acid levels was recorded in the $2^{\text {nd }}$ group. At the same time, in the same group of patients, there was a significant increase in plasma cystatin $C$ content $(p<0.05)$ and a decrease in calculated GFR $(\mathrm{p}<0.05)$. Evaluation of the relationship between the value of LVMI and clinical and laboratory parameters was carried out first in the general and in each group separately (Table 4). The presence of a reliable positive correlation relationship was obtained between the level of central BP ( $r=0.264$; $\mathrm{p}=0.003)$, the augmentation index $(\mathrm{r}=0.224 ; \mathrm{p}=0.011)$ and the concentration of cystatin $\mathrm{C}$ in the blood plasma ( $\mathrm{r}=0.486$; $\mathrm{p}=0.000)$ total sample. Feedback was observed between eGFR and LVMI ( $r=-$ $0.425 ; \mathrm{p}=0.000$ ). Similar correlation shifts with the exception of the augmentation index also occurred in the $1^{\text {st }}$ group (Table 4$)$. In the $2^{\text {nd }}$ group, a direct close direct connection was found between the content of cystatin C in blood plasma, the level of central BP with the value of LVMI.

Table 3: Parameters of biochemical analysis of blood of the examined groups.

\begin{tabular}{|c|c|c|c|}
\hline Indicators & 1-st group (n=111) & 2-nd group (n=65) & P= \\
\hline Cholesterol, $\mathrm{mmol} / \mathrm{l}$ & $4,75(4,0 ; 5,38)$ & $5,80(4,87 ; 6,80)$ & 0,000 \\
\hline HDL cholesterol, mmol/l & $1,18 \pm 0,30$ & $1,13 \pm 0,30$ & 0,045 \\
\hline Cholesterol LDL, mmol/l & $3,09(2,61 ; 3,79)$ & $3,56(3,12 ; 4,63)$ & 0,000 \\
\hline Triglycerides, mmol/l & $1,09(0,91 ; 1,36)$ & $2,42(1,97 ; 3,37)$ & 0,638 \\
\hline Calcium, mmol/l & $2,11 \pm 0,38$ & $2,14 \pm 0,33$ & 0,672 \\
\hline C-reactive protein, $\mathrm{n}(\%)$ & $31(27,9)$ & $20(30,7)$ & 0,088 \\
\hline Uric acid, mmol/l & $0,405 \pm 0,129$ & $0,531 \pm 0,136$ & 0,026 \\
\hline Cystatin C, mg/l & $1,16(0,99 ; 1,42)$ & $1,25(1,08 ; 1,70)$ & 0,028 \\
\hline eGFR, $\mathrm{ml} / \mathrm{min}$ & $65,0 \pm 23$ & $57,0 \pm 22$ & \\
\hline
\end{tabular}

Note: eGFR - estimated glomerular filtration rate. HDL cholesterol - high density lipoprotein cholesterol; LDL cholesterol - low density lipoprotein cholesterol; number of patients.

Table 4: Correlation analysis between clinical laboratory parameters and the value of LVMI in two groups.

\begin{tabular}{|c|c|c|c|c|c|c|}
\hline \multirow{3}{*}{$\begin{array}{l}\text { Independent } \\
\text { variables }\end{array}$} & \multicolumn{2}{|c|}{ General group $(n=176)$} & \multicolumn{2}{|c|}{ 1-st group $(n=111)$} & \multicolumn{2}{|c|}{ 2-nd group $(n=65)$} \\
\hline & \multicolumn{6}{|c|}{ The mass index of the myocardium of the left ventricle $\mathrm{g} / \mathrm{m}^{2}$} \\
\hline & $\mathrm{R}=$ & $\mathrm{P}=$ & $\mathrm{R}=$ & $P=$ & $\mathrm{R}=$ & $P=$ \\
\hline CAP, $\mathrm{mm} \mathrm{Hg}$ & 0,264 & 0,003 & 0,231 & 0,040 & 0,300 & 0,038 \\
\hline $\begin{array}{l}\text { Augmentation } \\
\text { index, } \%\end{array}$ & 0,224 & 0,011 & 0,184 & 0,103 & 0,277 & 0,050 \\
\hline Cystatin C, mg/I & 0,486 & 0,000 & 0,362 & 0,001 & 0,314 & 0,030 \\
\hline $\begin{array}{c}\text { Triglycerides, } \\
\mathrm{mmol} / \mathrm{l}\end{array}$ & 0,026 & 0,770 & 0,050 & 0,629 & 0,133 & 0,365 \\
\hline Uric acid, mmol/l & 0,020 & 0,820 & 0,005 & 0,997 & 0,021 & 0,884 \\
\hline eGFR, $\mathrm{ml} / \mathrm{min}$ & $-0,425$ & 0,000 & $-0,420$ & 0,000 & $-0,184$ & 0,210 \\
\hline
\end{tabular}

Note: CAP - central arterial pressure; eGFR - estimated glomerular filtration rate; $\mathrm{p}$ - reliability; $\mathrm{n}$ is the number of patients; $\mathrm{r}$ is the correlation coefficient.

\section{Discussion}

Despite advances in the study of diseases underlying CKD, the prognosis for this category of patients remains unfavorable. The concentration of TG-rich lipoproteins increases in the blood plasma at the early stages of CKD even at normal values of creatinine [19]. It should be noted that HTG is the most frequent variant of dyslipidemia in patients with kidney pathology $[20,21]$. A combination of HTG 
and an increase in the LV myocardium mass with a change in its geometry is believed to be associated with a further decrease in renal function and the risk of mortality, especially in the terminal stages of CKD $[22,23]$. It is important to note that HTG in patients of therapeutic profile has a double meaning. First, HTG is an important factor in the development and course of multifocal atherosclerosis and related cardiovascular complications. Secondly, an increase in the level of TG is directly related to the risk of developing renal dysfunction $[20,21,24]$. However, high TG levels are often combined with low HDL cholesterol levels and high LDL cholesterol levels. This fact is completely consistent with our results, i.e. in the group of patients with HTG, there was a statistically significant increase in the concentration of total cholesterol and LDL cholesterol (Table 3). Some meta-analyzes of TG are identified as an independent risk factor for CVD [24,25]. Moreover, recent genetic studies have confirmed the view that elevated TG is a direct cause of CVD development $[26,27]$. According to our data, among patients with HTG, the average eGFR was significantly lower (Table 3). It was established that a slight decrease in GFR is reflected by changes in the concentration of cystatin C in the blood [28].

Serum cystatin C levels are considered as a sensitive marker of the severity of renal dysfunction and the risk of LVH [29]. In studies A. Shankar et al. (2011), it has been shown that higher levels of cystatin $\mathrm{C}$ in individuals with CKD are associated with arterial hypertension [30]. In our study, we were also able to demonstrate a positive correlation between the content of cystatin $\mathrm{C}$ in blood and the value of LVMI in all groups (Table 4). The results of our work are consistent with data from other studies that have shown a relationship between elevated levels of cystatin $\mathrm{C}$ and LVH $[31,29]$. In persons with CKD, LVH is much more common, and the life expectancy of a patient with renal dysfunction and left ventricular hypertrophy is significantly reduced [32]. HTG also contributes to the occurrence of LVH in patients with CKD [20]. The presence of HTG stimulates the formation of adhesion molecules, the adherence of leukocytes to the surface of the endothelium, increases the secretory activity and proliferation of macrophages in the atherosclerotic plaque, activates the migration and proliferation of smooth muscle cells. A consequence of these effects is the development of endothelial dysfunction, increased stiffness of the vascular wall and myocardium [20,21]. Atherosclerotic changes in the arterial bed lead to ischemia of cardiomyocytes, activation of necrosis and apoptosis [33,34]. The decrease in the number of functioning cardiomyocytes, interstitial remodeling is accompanied by the development of both systolic and diastolic myocardial dysfunction [35].

We discovered a direct relationship between the magnitude of the augmentation index and the presence of LVH in the general group. A direct relationship was established between the increase in the augmentation index and the level of systolic blood pressure [36]. Was shown a close relationship of the blood lipid spectrum with vascular stiffness indicators [37]. The increase in the stiffness of large arteries plays an important role in the pathogenesis of many CVDs and, above all, in the development of hypertension [38,39]. On the other aspect, an increase in blood pressure causes changes in the vascular wall, incl. with the development of arteriosclerosis, which can lead to an increase in arterial stiffness of the renal arteries [40]. The augmentation index is a surrogate indicator of arterial stiffness and determines the state of the vascular bed from the central arteries to the microvasculature [41]. As a result of an increase in the augmentation index, the load on the LV increases, which certainly leads to the development of LVH $[42,43]$. Concentric hypertrophy is the most unfavorable type of remodeling, which is associated with the greatest number of complications [44-46]. The role of LVH and its relationship with the clinical and laboratory manifestations of CKD at the predialysis stage continue to be studied. According to the results of our study, HTG and LVH were reliably accompanied by an increase in systolic blood pressure, BMI, cystatin C, Cholesterol LDL and a decrease in GFR. The negative impact of these clinical and laboratory parameters on the LV myocardium was manifested by an increase in the number of patients with a concentric type of LVH.

\section{Conclusion}

Hypertriglyceridemia in patients with left ventricular hypertrophy is accompanied by an increase in blood cystatin $\mathrm{C}$, a decrease in GFR, and a tendency for augmentation index to increase.

\section{References}

1. ElHafeez SA, Bolignano D, D’Arrigo G (2018) Prevalence and burden of chronic kidney disease among the general population and high-risk groups in Africa: a systematic review. BMJ open 8(1): C. e015069. DOI: http://dx.doi.org/10.1136/bmjopen-2016-015069

2. Yao KH, Guehi MC, Konan SD (2018) Prevalence and risk factors for chronic kidney disease in general population of Yopougon (Côte d'ivoire); a cross-sectional study. J Renal Inj Prev 7(1): 27-32. DOI:10.15171/ jrip.2018.06

3. Moiseev VS, Mukhin NA, Smirnov AV (2014) Cardiovascular risk and chronic kidney disease: strategies for cardio-nephroprotection. Russian Cardiology Journal 18: 7-37.

4. Colina IB, Stavrovskaya U, Shilov EM (76) Dysli pidemia, and chronic progressive renal disease. Ter. archive 76 (9): 75-77.

5. Bhowmik D, Tiwari SC (2008) Metabolic syndrome and chronic kidney disease. Indian J. Nephrol 18 (1): 1-4.

6. Kaysen GA (2006) Dyslipidemia in chronic kidney disease: Causes and consequences. Kidney International 70: S55-S58. DOI: https://doi. org/10.1038/sj.ki.5001979.

7. Di Lullo L, Gorini A, Russo D (2015) Left ventricular hypertrophy in chronic kidney disease patients: from pathophysiology to treatment. Cardiorenal medicine 5(4): 254-266. DOI: https://doi. org/10.1159/000435838.

8. Foley RN, Parfrey PS, Harnett JD (1995) The prognostic importance of left ventricular geometry in uremic cardiomyopathy. J Am Soc Nephrol 5(12): 2024-2031.

9. Murkamilov IT, Aitbaev KA, Baysimakova FK (2017) Factors contributing to progression of glomerulonephritis and cardiovascular disorders. The 
Journal of Health and Education Millennium 19: 8: 32-39. DOI:10.26787/ nydha-2226-7425-2017-19-8-32-39.

10. Murkamilov IT, Aitbaev K A, Sarybaev A Sh (2018) Relationship of Remodeling of Carotid Patients with Chronic Glomerulonephritis. Kardiologiia 58(4): 45-52. DOI:10.18087/cardio.2018.4.10108.

11. Catapano AL, Graham I, De Backer G (2017) 2016 ESC / EAS Guidelines for the management of dyslipidaemias. Russian Journal of Cardiology (5): 7-77. https://doi.org/10.15829/1560-4071-2017-5-7-77.

12. Williams B, Mancia G, Spiering W (2018) 2018 ESC/ESH Guidelines for the management of arterial hypertension. European heart journal 39(33):3021-3104.

13. National Kidney Foundation (2002) K/DOQI clinical practice guidelines for kidney disease: evaluation, classification, and stratification. Am J Kidney Dis 39 (2 Suppl 1): S1-266.

14. Hoek FJ, Kemperman FA, Krediet RT (2003) A comparison between plasma cystatin C, plasma creatinine and the Cockcroft Gault. Nephrol Dial Transplant 18(10): 2024-2031. DOI: 10.1093/ndt/gfg349

15. Parfenov AS (2012) Early diagnosis of cardiovascular diseases using hardware-software complex "Engioscan -01". Poliklinika 2: 1:70-74

16. Teichholz LE, Kreulen T, Herman MV, Gorlin R (1976) Problems in echocardiographic volume determinations: echocardiographicangiographic correlation. American Journal of Cardiology 37(1): 7-11. DOI: https://doi.org/10.1016/0002-9149(76)90491-4.

17. Devereux RB, Reichek N (1977) Echocardiographic determination of the left ventricular mass in man. Anatomic validation of the method. Circulation. 1977; 55 (4) .613-618.

18. Grinhalh T (2004) Fundamentals of Evidence-Based Medicine. GEOTARMED, Moscow, Russia.

19. Tsimihodimos V, Mitrogianni Z, Elisaf M (2011) Dyslipidemia associated with chronic kidney disease. The open cardiovascular medicine journal 5: 41-48. DOI:10.2174/ 1874192401105010041.

20. Mukhin NA (2016) Nephrology. National leadership. Short edition. Moscow, Russia.

21. IE Tareeva (2000) Nephrology. Practical guide. ( $2^{\text {nd }}$ Edn.) Pererab and additional Medicine.

22. Visconti L, Benvenga S, Lacquaniti A (2016) Lipid disorders in patients with renal failure and chronic kidney disease. Journal of Clinical \& Translational Endocrinology 6: 8-14. DOI: 10.1016/j.jcte.2016.08.002.

23. Lacquaniti A, Bolignano D, Donato V (2010) Alterations of lipid metabolism in chronic nephropathies: mechanisms, diagnosis and treatment. Kidney Blood Press Res 33(2): 100-110.

24. Jørgensen AB, Frikke-Schmidt R, West AS (2013) Genetically elevated non-fasting triglycerides and calculated remnant cholesterol risk factors for myocardial infarction. Eur Heart J 34 (24): 1826-1833. DOI:10.1093/ eurheartj/ehs431.

25. Do R, Willer CJ, Schmidt EM (2013) Common variants associated with plasma triglycerides and risk for coronary artery disease. Nat Genet 45 (11): 1345-1352. DOI:10.1038/ng.2795.

26. Whitfield JB (2014) Genetic insights into cardiometabolic risk factors. The Clinical Biochemist Reviews 35(1): 15-36.

27. Chapman MJ, Ginsberg HN, Amarenco P (2011) Triglyceride-rich lipoproteins and high-density lipoprotein cholesterol. European heart journal 32(11): 1345-1361. DOI: https://doi.org/10.1093/eurheartj/ ehr112.

28. Murkamilov IT, Fomin VV, Aitbaev KA (2018) Blood plasma cystatin c level and its relationship with the augmentation index and central arterial pressure in therapeutic patients. Clinical nephrology 3: 31-40. DOI:10.18565/nephrology.20183.31-40.
29. Vasilieva MP, Rudenko TE, Kutyrina IM, Solomakhina NI (2015) Cystatin $\mathrm{C}$ is a new marker of myocardial hypertrophy of the left ventricle in patients with chronic kidney disease. Ter. Archive 87(6): 17-22.

30. Shankar A, Teppala S (2011) Relationship between serum cystatin C and hypertension among US adults without clinically recognized chronic kidney disease. J Am Soc Hypertens 5(5): 378-384. DOI: 10.1016/j. jash.2011.03.003.

31. Prats M, Font R, Bardají A (2010) Cystatin C and cardiac hypertrophy in primary hypertension. Blood pressure19(1): 20-25. DOI: https://doi. org/10.3109/08037050903416386.

32. Foley RN, Parfrey PS, Harnett JD (1995) Clinical and echocardiographic disease in patients starting end-stage renal disease therapy. Kidney international 47(1):186-192. DOI: https://doi.org/10.1038/ki.1995.22.

33. Pangonytė D, Stalioraitytė E, Žiuraitienè R (2008) Cardiomyocyte remodeling in ischemic heart disease. Medicina 44(11): 848-854.

34. Pothineni NVK, Karathanasis SK, Ding Z (2017) LOX-1 in atherosclerosis and myocardial ischemia: biology, genetics, and modulation. Journal of the American College of Cardiology 69(22): 2759-2768. DOI: https:// doi.org/10.1016/j.jacc.2017.04.010.

35. Kremneva LV, Shalaev SV (2004) Modificirovannye lipoproteiny nizkoj plotnosti: aterogennaya i provospalitel'naya aktivnost', rol'v patogeneze ostryh koronarnyh sindromov. Ross. Kardiol. Zhurnal 46 (2):70-75.

36. Kravtsova OA, Pavlova EA, Kotovskaya Yu V, Kobalava ZhD (2014) It is recommended that patients have previously untreated arterial hypertension. Rational pharmacotherapy in cardiology 10 (1): 31-36.

37. Isaykina OY, Rozanov VB, Zvolinskaya EY, Pugoeva HS, Alexandrov AA (2017) Arterial Stiffness and Cardiovascular Risk Factors in Young Men (41-44 Years). Rational Pharmacotherapy in Cardiology 13 (3): 290-300.

38. Sun Z (2015) Aging, arterial stiffness, and hypertension. Hypertension 65(2): 252-256. DOI:10.1161/Hypertensionaha.114.03617.

39. Dumor K, Shoemaker-Moyle M, Nistala R, Whaley-Connell A (2018) Arterial Stiffness in Hypertension: An Update. Curr Hypertens Rep 20(8): 72. DOI:10.1007/s11906-018-0867-x.

40. Ao DH, Zhai FF, Han F (2003) Large vessel disease modifies the small vessel disease. Frontiers in neurology 9: 498. DOI: https://doi. org/10.3389/fneur.2018.00498.

41. Laurent S, Katsahian S, Fassot C (2003) Aortic stiffness in essential hypertension. Stroke 34(5): 1203-1206.

42. Garg S, de Lemos JA, Matulevicius SA (2017) Association of Concentric Left Ventricular Hypertrophy with the Endall Diastolic Volume: The Dallas Heart Study. Circ Heart Fail 10: e003959. DOI:10.1161/ Circheartfailure.117.003959.

43. Nicolas Debry, Sylvestre Maréchaux, Dan Rusinaru, Marcel Peltier, David Messika-Zeitoun et al. (2017) Prognostic significance of left ventricular concentric remodeling in patients with aortic stenosis. Archives of cardiovascular diseases110(1): 26-34. DOI: https://doi.org/10.1016/j. acvd.2016.05.010.

44. Ramirez Sandoval JC, Madero M (2018) Treatment of Hyperuricemia in Chronic Kidney Disease. Uric Acid in Chronic Kidney Disease. Karger Publishers 192: 135-146. DOI: https://doi.org/10.1159/000484288.

45. Murkamilov IT, Sabirov IS, Fomin VV (2018) Hyperuricemia in chronic glomerulonephritis: clinical and functional features. Clinical nephrology 1: $31-37$.

46. Eleftheriadis T, Golphinopoulos S, Pissas G, Stefanidis I (2017) Asymptomatic hyperuricemia and chronic kidney disease: Narrative review of a treatment controversial. Journal of advanced research 8(5): 555-560. DOI: https://doi.org/10.1016/j.jare.2017.05.001. 
DOI: 10.32474/JUNS.2018.01.000115

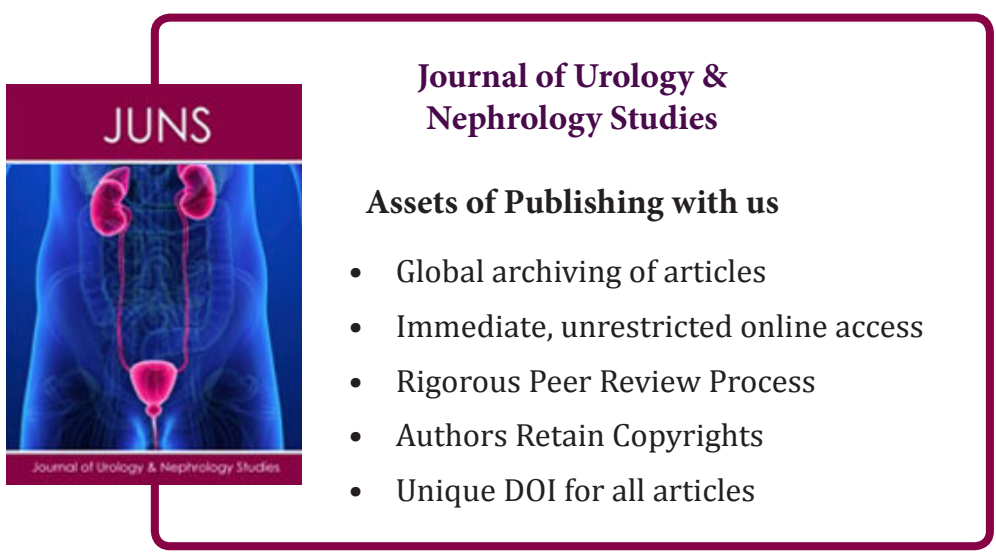

